\title{
Regeneration of Protoplasts of Bacillus subtilis 168 and Closely Related Strains
}

\author{
By N. BOLRNE AND B. N. DANCER \\ Department of Applied Biologl, UWIST, PO Box 13, Cardiff CFI $3 X F, U K$
}

(Receiced 16 July 1985; revised 24 September 1985)

\begin{abstract}
Regeneration of protoplasts to bacilli was attempted in several strains of Bacillus closely related to Bacillus subtilis 168. On DM3 and similar media using succinate as osmotic support, only $B$. subtilis 168 and Bacillus natto ATCC 15245 were able to regenerate. Media containing mannitol as osmotic support, and agar as gelling agent gave rise to L-form colonies with Bacillus licheniformis NCTC 6346. Many of the L-form colonies were able to regenerate to the bacillary form when plated on the mannitol medium solidified with gelatin. All of the Bacillus species tested were able to regenerate on the latter medium at rates sufficient to allow protoplast transformation and fusion experiments.
\end{abstract}

\section{INTRODUCTION}

There is increasing interest in the use of protoplast-mediated techniques such as fusion (Fodor \& Alföldi, 1976; Schaeffer et al., 1976) and transformation (Chang \& Cohen, 1979) for the genetic study and manipulation of Bacillus species. To use these techniques effectively it is necessary to have methods that allow quantitative conversion of cells to protoplasts and subsequent reversion to the bacillary form. Such systems are established for a few species including Bacillus subtilis 168 (Landman et al., 1968) and Bacillus megaterium K M (Fodor et al., 1975) but not for many others.

Strains of Bacillus produce a wide range of products of potential and frequently real industrial importance. Food-grade and other exoenzymes (Priest, 1977), antibiotics (Katz \& Demain, 1977), entomotoxins (de Barjac, 1981) and other products are produced by strains for which gene transfer techniques to permit genetic analysis are seldom available. It is likely that the actual processes of protoplast fusion and transformation would vary little from one Bacillus species to another so that these techniques could have wide-ranging applications. However, it seems that few Bacillus species regenerate on the media that are effective for $B$. subtilis 168 and $B$. megaterium KM. By adopting an ad hoc approach to formulation a number of groups have described regeneration media for use with individual species, e.g. Bacillus sphaericus (McDonald \& Burke, 1984); Bacillus popilliae and Bacillus larvae (Bakhiet \& Stahly, 1985); Bacillus stearothermophilus (Imanaka et al., 1982). However, with some exceptions, rates of regeneration from protoplasts to bacilli remain poor and variable. We have tried to establish more general conditions and have developed media that allow regeneration of a number of strains closely related to $B$. subtilis 168 .

\section{METHODS}

Strains and growth conditions. The bacterial strains were chosen to represent a range of bacilli all relatively closely related to B. suhtilis 168 (Seki ${ }^{\prime} t a l ., 1979$ ). They include representatives that produce extracellular amylases, proteases, $\beta$-lactamase and polyglutamic acid (Table l). Stocks of bacteria were maintained in $5^{\circ}{ }_{0}(v)$ glycerol at -70 ' C

The composition of the liquid growth medium was found in preliminary experiments to have an important effect on subsequent quantitative conversion of cells to protoplasts. Cells grown in the absence of sugars were 
Table 1. Bacterial strains

Strain

B. subtilis 168 (trpC2)

B. licheniformis NCTC 6346 ( His $^{-}$)

B. licheniformis NCIB 8874

B. licheniformis ATCC 10716

B. licheniformis $749 / \mathrm{C}$

B. glohigii NCIB 8649

B. amyloliquefaciens NCIB 10785

B. subtilis NCIB 8565

B. natto ATCC 15245

B. pumilis $8 \mathrm{Al}$

Bacillus sp. N7

Bacillus sp. 16A
Product

$\left.\begin{array}{c}- \\ \text { Bacitracin } \\ \text { Bacitracin } \\ \beta \text {-Lactamase } \\ \alpha- \\ \alpha \text {-Amylase } \\ \beta \text {-Glucanase } \\ \text { Polyglutamate } \\ - \\ \alpha \text {-Amylase } \\ \alpha \text {-Amylase }\end{array}\right\}$

Source or reference*

J. Mandelstam, Oxford University, UK Elliott et al. (1975)

NCIB

ATCC

J. O. Lampen, Rutgers University, NJ, USA

R. Sharp, CAMR, Porton, UK

NCIB

Hinchliffe (1984)

ATCC

BGSC

R. Piggot, Biocon Ltd, Carrigaline, Fire

* NCIB, National Collection of Industrial Bacteria, Aberdeen; ATCC, American Type Culture Collection, Rockville, Md, USA; BGSC, Bacillus Genetic Stock Center, University of Ohio, USA.

converted to protoplasts more readily and synchronously than cells grown in sugar-supplemented media or rich, undefined media, such as tryptone soya broth, so that only a low background of lysozyme-resistant cells remained. The preferred growth medium was minimal salts (Spizizen, 1958) supplemented with $1 \%(\mathrm{w} / \mathrm{v})$ Bacto Casamino acids (Difco) and $20 \mu \mathrm{g}$ tryptophan $\mathrm{ml}^{-1}$. However, for Bacillus natto this medium was insufficient and so tryptone soya broth, despite its disadvantages, was used.

Cultures were inoculated from fresh nutrient agar (NA) stock plates and shaken overnight at $30^{\circ} \mathrm{C}$. The following morning cultures with an $\mathrm{OD}_{600}$ of less than 0.6 , and which had not sporulated were used to inoculate fresh medium to an $\mathrm{OD}_{600}$ of approx. $0 \cdot 01$. The subcultures rapidly attained exponential phase on shaking at $37^{\circ} \mathrm{C}$ and when the $\mathrm{OD}_{600}$ reached approx. $0 \cdot 5$ the cells were harvested by centrifugation.

Preparation of protoplasts. Pellets of harvested cel s were resuspended in a 0.1 volume of osmotically-supported protoplast buffer. A viable count was taken by diluting cells in growth medium and plating on NA. Hen egg white lysozyme (Sigma) was added to a final concentration of $100 \mu \mathrm{g} \mathrm{ml}^{-1}$ and the culture incubated with shaking for $20 \mathrm{~min}$ at $37^{\circ} \mathrm{C}$. Protoplast formation was assessed semiquantitatively by phase-control microscopy and, if a significant proportion of bacillary cells remained $(>1 \%)$, incubation was continued for up to $60 \mathrm{~min}$. Once satisfactory protoplast formation had occurred a second viable count was taken, as before, to determine the number of lysozyme-resistant survivors.

The protoplast buffer used was tryptone/yeast extract/sucrose (TYS; Elliott et al., 1975) supplemented with $1 \%$ $(w / v)$ bovine serum albumin (Sigma fraction $V$ ) and sterilized by filtration.

Cell wall regeneration. Protoplasts were diluted in TYS buffer and spread on osmotically-supportive regeneration agar plates. The plates were incubated at $30^{\circ} \mathrm{C}$ until no further colonies appeared (up to $10 \mathrm{~d}$ ).

Three regeneration media were tested. DP (Elliott et al., 1975) and DM3 (Chang \& Cohen, 1979) use succinate for osmotic support. MRA is a mannitol-based medium described by Nimi et al. (1983) for regeneration of Bacillus breris protoplasts. Modifications of these media are described, where appropriate, in the results.

Mean chain length. Bacillus strains often form chains of cells, the mean length of which varies. Conversion of cells to protoplasts incidentally causes dechaining so that the apparent initial viable count (i.e. colony forming units) is an underestimate with regard to potential regenerants from a culture of protoplasts. To correct for this, mean chain lengths of cells in cultures were determined immediately before lysozyme addition. A drop of culture was mixed with a drop of saturated $\mathrm{CsCl}$ solution and the plasmolysed cells were viewed by phase-contrast microscopy. The cell content of 300 chains was courted for each culture and the mean chain length determined.

The initial viable count was calculated as the product of colony forming units and mean chain length. Regeneration is then given as the ratio (bacillary colony count on regeneration medium - survival count on NA)/ (initial viable count). This assumes that lysozyme-resistant survivors are either dechained or that only one cell per chain is resistant.

\section{RESULTS AND DISCUSSION}

In initial experiments cells were converted to protoplasts in TYS buffer and regeneration to bacilli was tested on DM3 medium. Typical results for lysozyme survival and protoplast regeneration are shown in Table 2 . For all strains tested at least $99.5 \%$ of cells were converted to protoplasts. $B$. subtilis $168, B$. natto and to a lesser extent $B$. subtilis 8565 regenerated readily at 
Table 2. Typical values for frequencies of lysozyme resistance and regeneration

Values were determined as described in Methods and mean chain lengths are the results of observations of 300 chains. Initial viable counts were all in the range $6 \times 10^{8}$ to $6 \times 10^{9}$.

\begin{tabular}{|c|c|c|c|c|c|}
\hline \multirow[b]{2}{*}{ Strain } & \multirow{2}{*}{$\begin{array}{l}\text { Mean } \\
\text { chain } \\
\text { length }\end{array}$} & \multirow{2}{*}{$\begin{array}{l}\text { Lysozyme } \\
\text { resistance } \\
\text { frequency }\end{array}$} & \multicolumn{2}{|c|}{ Regeneration frequency } & \multirow{2}{*}{$\begin{array}{c}\text { Improved } \\
\text { regeneration } \\
\text { with MRG } \\
\text { (fold) }\end{array}$} \\
\hline & & & DM3 medium & MRG medium & \\
\hline B. subtilis 168 & 2.60 & $1.05 \times 10^{-3}$ & $1.30 \times 10^{-1}$ & $1.27 \times 10^{-1}$ & 1 \\
\hline B. licheniformis 6346 & $1 \cdot 26$ & $1.20 \times 10^{-4}$ & $1.42 \times 10^{-4}$ & $2.32 \times 10^{-2}$ & 163 \\
\hline B. licheniformis 8874 & $2 \cdot 33$ & $1.44 \times 10^{-5}$ & $3.42 \times 10^{-5}$ & $1.51 \times 10^{-2}$ & 442 \\
\hline B. licheniformis 10716 & 1.80 & $1.86 \times 10^{-4}$ & $5.02 \times 10^{-5}$ & $5.04 \times 10^{-3}$ & 100 \\
\hline B. licheniformis $749 / C$ & 1.47 & $5.66 \times 10^{-5}$ & $4.91 \times 10^{-5}$ & $4.16 \times 10^{-2}$ & 847 \\
\hline B. globigii 8649 & $1 \cdot 82$ & $2.00 \times 10^{-3}$ & $5.09 \times 10^{-3}$ & $7.06 \times 10^{-2}$ & 14 \\
\hline B. amyloliquefaciens 10785 & $9 \cdot 48$ & $5 \cdot 20 \times 10^{-6}$ & $5.84 \times 10^{-5}$ & $3.91 \times 10^{-3}$ & 67 \\
\hline B. subtilis $8565^{*}$ & 1.63 & $1.45 \times 10^{-3}$ & $1.33 \times 10^{-2}$ & $1.12 \times 10^{-1}$ & 8 \\
\hline B. natto 15245 & $17 \cdot 80$ & $2.66 \times 10^{-7}$ & $5.05 \times 10^{-2}$ & $1.14 \times 10^{-2}$ & $0 \cdot 2$ \\
\hline B. pumilis $8 \mathrm{Al}$ & 1.29 & $1.27 \times 10^{-6}$ & $1.49 \times 10^{-3}$ & $2.04 \times 10^{-2}$ & 14 \\
\hline Bacillus sp. N7 & $3 \cdot 08$ & $6.27 \times 10^{-5}$ & $7 \cdot 17 \times 10^{-3}$ & $1.95 \times 10^{-2}=$ & 3 \\
\hline Bacillus sp. 16A & $13 \cdot 47$ & $1.54 \times 10^{-6}$ & ND & $1.78 \times 10^{-2}$ & - \\
\hline
\end{tabular}

rates significantly above the lysozyme survival counts. The rates of regeneration are lowered by the correction for mean chain length. Without this correction, apparent regeneration frequencies would have been $3.38 \times 10^{-1}$ for $B$. subtilis 168 and $8.99 \times 10^{-1}$ for $B$. natto. The uncorrected value for $B$. subtilis 168 is comparable with that obtained by other workers (e.g. Schaeffer $e t$ al., 1976) and the rate for $B$. natto in particular illustrates the error that can occur due to dechaining. Apart from these two strains, the regeneration frequencies obtained with DM3 medium were generally very low. The failure of Bacillus licheniformis 6346 to regenerate was particularly unexpected since Elliott et al. (1975) using similar conditions observed regeneration sufficiently well to allow biochemical and physiological investigations of the process. We therefore concentrated on establishing regeneration conditions for B. licheniformis 6346 to the temporary exclusion of the other strains.

DP medium (Elliott et al., 1975) and DM3 medium (Chang \& Cohen, 1979) are both modifications of the DPA medium of Wyrick \& Rogers (1973). DM3 was used by Chang \& Cohen (1979) because with $B$. subtilis 168 it reduced the time required for cell wall regeneration and eliminated the crowding effect reported by Schaeffer et al. (1976). It was possible that modification had made the medium unsuitable for regeneration of $B$. licheniformis 6346 protoplasts. However, in a comparison experiment it was shown that while DM3 medium is clearly superior to DP for cell wall regeneration of $B$. subtilis 168 (regeneration frequencies of $2.73 \times 10^{-2}$ and $1.24 \times 10^{-2}$ respectively), B. licheniformis 6346 protoplasts failed to regenerate significantly for practical purposes on either medium (regeneration frequencies of $1.45 \times 10^{-4}$ on DM3 and $9.26 \times 10^{-5}$ on DP), despite using identical strains and conditions as close as possible to those of Elliott et al. (1975). This highlights a problem with regeneration media, in that they are complex in composition and there are reports of batch-to-batch variation of media greatly affecting rates of regeneration (King \& Gooder, 1970). Thus many components may be changed or modified without significant improvement in regeneration. Moreover, it is possible that the growth medium and protoplast buffer could have effects on subsequent regeneration. We have tried many modifications to the media and conditions without significantly increasing the rate of regeneration.

An alternative to testing further modifications of DM3 was to use a new medium altogether. A mannitol-based regeneration medium (MRA) described by Gray \& Chang (1981) and modified by Nimi et al. (1983) for regeneration of $B$. brevis protoplasts was chosen. With $B$. licheniformis 6346 the count of bacillary colonies was as low as that on DM3 medium. However, L-form 
colonies, representing about $30 \%$ of the ir itial viable count, developed on MRA but not on DM3 medium. The problem remained then to find conditions that would allow L-form reversion.

Spontaneous reversion of L-forms to bacilli after prolonged incubation has been reported for B. subtilis 168 (Landman \& Halle, 1963). However, incubation prolonged for $10 \mathrm{~d}$ led to no significant reversion of the L-forms of B. licheniformis 6346 on MRA medium. Landman et al. (1968) reported that gelatin $(25 \%, \mathrm{w} / \mathrm{v})$ as sole gelling agent was effective in allowing reversion of L-forms and regeneration of protoplasts of $B$. subtilis 168 to the bacillary state. When we used $25 \%(\mathrm{w} / \mathrm{v})$ gelatin as sole gelling agent (MRG medium) a significant increase in regeneration of protoplasts of $B$. licheniformis 6346 was obtained (Table 2). The number of bacillary colonies formed was not as great as the number of $\mathrm{L}$-form colonies formed on MRA but, nevertheless, the extent of regeneration would be sufficient to allow protoplast-mediated gene-transfer techniques to be used in this organism.

The other Bacillus species used in this investigation were also able to regenerate on MRG (Table 2). B. subtilis 168 regenerated to about the same extent on DM3 and MRG, and B. natto regenerated better on DM3. Nevertheless, in the latter case, rates of regeneration on MRG are sufficient to allow its use, if a series of experiments require that only a single regeneration medium be used. In all other cases, MRG medium allowed more extensive regeneration than DM3. The most marked improvements were seen with the $B$. licheniformis strains and $B$. amyloliquefaciens, and even though the rates of regeneration are still quite low in some cases, in practice they are suffcient to allow effective uptake of plasmids in protoplast transformations (unpublished observation). $\mathrm{MRG}$ is inconvenient to make up and requires incubation at $30^{\circ} \mathrm{C}$ or below. Liquefaction of the gelatin by some strains causes difficulties on extended incubation but this can be avoided by enumerating and subculturing early. Despite these problems the use of MRG significantly extends the range of Bacillus strains available for protoplast-mediated genetic experiments to include many strains of interest as exoenzyme producers (e.g. $B$. amyloliquefaciens, Bacillus sp. N7, Bacillus sp. 16A) and antibiotic producers (e.g. B. licheniformis $10716, B$. licheniformis 8874). Thus, genetic analysis and manipulation of these strains of practical importance becomes more feasible.

N. B. was supported in this work by a postgraduate studentship from the Science and Engineering Research Council. Our thanks to those who generously provided us with strains.

\section{REFERENCES}

Bakhif, N. \& Stahly, D. P. (1985). Studies on transfection and transformation of protoplasts of Bacillus larrae, Bacillus suhtilis, and Bacillus popilliae. Applied and Encironmental Microhiolog. 49, $577-581$.

DE BARJAC, H. (1981). Insect pathogens in the genus Bacillus. In The Aerobic Endospore-forming Bacteria, pp. 24l-250. Edited by R. C. W. Berkeley \& M. Goodfellow. London: Academic Press.

Chang, S. \& Cohen, S. N. (1979). High frequency transformation of Bacillus subtilis protoplasts by plasmid DNA. Molecular and General Genetics 168. 111115.

Elliott, T. S. J., WARD, J. B. \& Rogers, H. J. (1975). Formation of cell wall polymers by reverting protoplasts of Bacillus licheniformis. Journal of Bacteriology' 124, 623-632.

FODOR, K \& ALFÖLDI, L. (1976). Fusion of protoplasts of Bacillus megaterium. Proceedings of the National Academy of Sciencess of the United States of America 73, 21472150 .

FOdOR, K., HadlaczKy, G. \& AlFöldi, L. (1975). Reversion of Bacillus megaterium protoplasts to the bacillary form. Journal of Bacteriology 121, 390) 391.

GRAY, O. \& Chang, S. (1981). Molecular cloning and expression of Bacillus licheniformis $\beta$-lactamase gene in Escherichia coli and Bacillus subtilis. Journal of Bacteriology 145, 422-428.

Hinchliffe, F. (1984) Cloning and expression of a Bacillus subtilis endo-1,3-1,4- $\beta$-D-glucanase gene in Escherichia coli K 12. Journal of General Microhiolog! 130, 12851291.

Imanaka, T., Fujil, M., Aramori, I. \& Aiba, A (1982). Transformation of Bacillus stearothermophilus with plasmid DNA and characterization of shuttle vector plasmids between Bacillus stearothermophilus and Bacillus suhtilis. Journal of Bacteriology 149,824830.

KatZ, E. \& Demain, A. L. (1977). The peptide antibiotics of Bacillus: chemistry, biogenesis and possible functions. Bacteriological Retiens 41, 449474.

KING, J. R. \& GoOder, H. (1970). Reversion of the streptococcal state of enterococcal protoplasts, spheroplasts, and L-forms. Journal of Bacteriology 103, 692-696

Landman, O. E. \& Halle, S. (1963). Enzymically and physically induced inheritance changes in Bacillus subtilis. Journal of Molecular Biology 7. 721738

Landman, O. E., Ryter, A. \& Frehel, C. (1968). Gelatin-induced reversion of protoplasts of Bacillus subtilis to the bacillary form: electron-microscope 
and physical study. Journal of Bacteriology 96, 21542170.

McDonald, K. O. \& Burke, W. F., JR (1984). Plasmid transformation of Bacillus sphaericus 1593. Journal of General Microbiology 130, 203-208.

Nimi, O., Kubo, M. \& Sugiyama, M. (1983). Protoplast formation and the regeneration of Bacillus brevis ATCC 9999 and its mutants. Biotechnology Letters 5, 709-714.

Priest, F. G. (1977). Extracellular enzyme synthesis in the genus Bacillus. Bacteriological Reviews 41, 711753.

Schaeffer, P., Cami, B. \& Hotchiss, R. D. (1976). Fusion of bacterial protoplasts. Proceedings of the National Academy of Sciences of the United States of America 73, 2151-2155.
Seki, T., Tsunekawa, H., Nakamura, K., YoshimURA, K. \& Oshima, Y. (1979). Conserved genes in Bacillus subtilis and related species. Journal of Fermentation Technology 57, 488-504.

Spizizen, J. (1958). Transformation of biochemically deficient strains of Bacillus subtilis by deoxyribonucleate. Proceedings of the National Academy of Sciences of the United States of America 44, 10721078.

WYRICK, P. B. \& Rogers, H. J. (1973). Isolation and characterization of cell wall-defective variants of Bacillus subtilis and Bacillus licheniformis. Journal of Bacteriology 116, 456-465. 